\title{
Spatial organization of fibroblast and spermatocyte nuclei with different $B$ chromosome content in Korean field mouse Apodemus peninsulae (Rodentia, Muridae)
}

\begin{tabular}{|c|c|}
\hline Journal: & Genome \\
\hline Manuscript ID & gen-2017-0029.R2 \\
\hline Manuscript Type: & Article \\
\hline Date Submitted by the Author: & 03-May-2017 \\
\hline Complete List of Authors: & $\begin{array}{l}\text { Karamysheva, Tatyana V.; Institute of Cytology and Genetics of the } \\
\text { Siberian Branch of the Russian Academy of Sciences, } \\
\text { Torgasheva, Anna; Insitute of Cytology and Genetics Siberian Branch of } \\
\text { Russian Academy of Sciences; Novosibirsk State University } \\
\text { Yefremov, Yaroslav; Institute of Cytology and Genetics, Siberian Branch of } \\
\text { Russian Academy of Sciences; Novosibirsk State University } \\
\text { Bogomolov, Anton; Institute of Cytology and Genetics, Siberian Branch of } \\
\text { Russian Academy of Sciences; Novosibirsk State University } \\
\text { Liehr, Thomas; Universitatsklinikum, Human Genetics } \\
\text { Borodin, Pavel; Institute of Cytology and Genetics Siberian Branch of } \\
\text { Russian Academy of Sciences; Novosibirsk State University } \\
\text { Rubtsov, Nikolay; Institute of Cytology and Genetics Siberian Branch of } \\
\text { Russian Academy of Sciences; Novosibirsk State University }\end{array}$ \\
\hline \multirow[t]{2}{*}{$\begin{array}{l}\text { Is the invited manuscript for } \\
\text { consideration in a Special } \\
\text { Issue? : }\end{array}$} & This submission is not invited \\
\hline & $\begin{array}{l}\text { B-chromosomes (Bs), A chromosomes (As), three-dimensional (3D) } \\
\text { architecture of the nucleus, fluorescence in situ hybridization on three- } \\
\text { dimensionally preserved nuclei (3D-FISH), confocal microscopy }\end{array}$ \\
\hline
\end{tabular}




\section{Original Research}

\section{Spatial organization of fibroblast and spermatocyte nuclei with different B chromosome content in Korean field mouse Apodemus peninsulae (Rodentia, Muridae)}

Tatyana V. Karamysheva ${ }^{1 *}$, Anna A. Torgasheva ${ }^{1}$, Yaroslav R. Yefremov ${ }^{1,2}$, Anton G. Bogomolov $^{1,2}$, Thomas Liehr ${ }^{3}$, Pavel M. Borodin ${ }^{1,2}$, Nikolay B. Rubtsov ${ }^{1,2}$

${ }^{1}$ Institute of Cytology and Genetics, Siberian Branch of Russian Academy of Sciences, 630090 Novosibirsk, Russia

${ }^{2}$ Novosibirsk State University, 630090 Novosibirsk, Russia;

${ }^{3}$ Jena University Hospital, Friedrich Schiller University, Institute of Human Genetics, Kollegiengasse 10, D-07743 Jena, Germany

* Correspondence Dr. Tatyana V. Karamysheva

Institute of Cytology and Genetics, Siberian Branch of Russian Academy of Sciences, Lavrentyev av.10, Novosibirsk 630090 (Russia)

phone: +73833634903 ; fax: +73833331278

e-mail: kary@bionet.nsc.ru 


\begin{abstract}
Korean field mouse (Apodemus peninsulae) shows a wide variation in the number of $\mathrm{B}$ chromosomes composed of constitutive heterochromatin. For this reason, it provides a good model to study the influence of the number of centromeres and amount of heterochromatin on spatial organization of interphase nuclei. We analyzed the three-dimensional organization of fibroblast and spermatocyte nuclei of the field mice carrying different number of $\mathrm{B}$ chromosomes using laser scanning microscopy and 3D fluorescence in situ hybridization. We detected a co-localization of the $\mathrm{B}$ chromosomes with constitutive heterochromatin of the chromosomes of the basic set. We showed not random distribution of B chromosomes in the spermatocyte nuclei. Unpaired B chromosomes showed tendency to occur in the compartment formed by unpaired part of XY-bivalent.
\end{abstract}

Key words: B-chromosomes (Bs), A chromosomes (As), three-dimensional (3D) architecture of the nucleus, fluorescence in situ hybridization on three-dimensionally preserved nuclei (3DFISH), confocal microscopy, spermatocytes, centromeres. 


\section{Introduction}

In eukaryotes, three-dimensional (3D) organization of the interphase nucleus is fairly complex and dynamic. It remains an area of intense research. Studies of DNA distribution within nuclei range from the analysis of physical interactions between short DNA fragments (Yaffe and Tanay 2011; Dostie and Bickmore 2012) to mapping of chromosome territories (Lemke et al. 2002; Manvelyan et al. 2008; Cremer and Cremer 2010) and the influence of small supernumerary marker chromosomes on interphase architecture (Klein et al. 2012; Karamysheva et al. 2015). For many cell types non-random distribution of transcriptionally active and nonactive chromatin in nucleus is well described (Bickmore 2013). Overall, the architecture of the interphase nucleus obviously provides an optimal spatial arrangement of chromatin containing active genes and regulatory elements (Schneider and Grosschedl 2007). In mammals the most typical organization of the nucleus includes localization of chromosomal heterochromatic regions in nuclear periphery near or in contact with the lamina and also around nucleoli, whereas chromosomal regions containing transcriptionally active genes are mostly located into internal compartment of the nucleus (Boyle et al. 2001; Cremer and Cremer 2001; Manvelyan et al. 2008). The spatial distribution of active and inactive genes allows considering the architecture of the interphase nucleus as one of the mechanisms involved in regulation of DNA transcriptional activity. Thus, structural and functional plasticity of interphase chromosome organization seems to be important for cell proliferation and differentiation. Pericentromeric C-positive regions of chromosomes consist of repetitive DNA and locate into nuclear periphery (Karamysheva et al. 2002, 2010; Trifonov et al. 2002; Weierich et al. 2003; Rubtsov et al. 2004, 2011); in interphase nucleus they usually form chromocenters (Alcobia et al. 2000) which vary in number and size, depending on cell type and stage of the cell cycle (Solovei et al. 2004; Carvalho et al. 2001).

Heterochromatin location in nuclear periphery was described in many mammalian species, despite of the great variation of heterochromatic volume observed even in closely 
related species and/or within the same species (Karamysheva et al. 2010; Rubtsov et al. 2011). Thus, variation in number and size of C-positive chromosomal regions including repetitive DNA and variation in centromere number might affect the architecture of the interphase nucleus. However, the question if there is an influence of the heterochromatic volume on evolutionary adaptive capacity of individual animals remains open.

The Korean field mouse (Apodemus peninsulae $=$ Ape) is a good model for studying the influence of additional C-positive chromosome regions and centromeres on the spatial nuclear organization. The diploid set of A chromosomes (As) in Ape consists of 48 acrocentrics, gradually decreasing in size, with NORs in the subtelomeric regions of the long arms of two pairs of chromosomes (Volobuev and Timina 1979; Kartavtseva 2002; Rubtsov et al. 2004). Cpositive regions of the As include autosomal pericentromeric regions, intercalary C-block in the $\mathrm{X}$-, and distant subtelomeric region in the Y-chromosome (Kartavtseva et al. 2000; Karamysheva et al. 2002, 2010; Trifonov et al. 2002; Rubtsov et al. 2004, 2011). The number of B chromosomes (Bs) varies from 0 to 24 (Volobuev and Timina 1979; Karamysheva et al. 2002, 2010). The Bs may vary in size from dot-like to the largest chromosome of the karyotype, and consist mainly of repetitive DNA (Rubtsov et al. 2015). Three types of repeat enriched regions of the A chromosomes (As) and Bs were described: (i) repeats clustered in pericentromeric regions of autosomes and in some Bs, in the intercalary C-band in the $\mathrm{X}$, and in the C-block in the distal region of the long arm of the $\mathrm{Y}$; (ii) repeats characteristic to many regions in the arms of the Bs, but absent in C-positive regions of As; (iii) repeats exclusively present in low condensed regions of the Bs (Karamysheva et al. 2002, 2010, Rubtsov et al. 2004, 2011).

The present study was devoted to analyze the spatial distribution of the Bs in fibroblast and spermatocyte nuclei of Ape with different sets of Bs, and consequently different numbers of centromeric regions and volumes of heterochromatin.

\section{Materials and Methods}




\section{Zoological specimens}

Ten males of Korean field mouse (Ape) were collected from natural populations. Specimens \#1 and \#2 derived from Altai Republic, near Turochak village $\left(52.25^{\circ} \mathrm{N}, 87.11^{\circ} \mathrm{E}\right)$. Specimens \#3, \#4, \#5, and \#10 were collected in outskirts of Novosibirsk city $\left(52.82^{\circ} \mathrm{N}, 83.09^{\circ}\right.$ E). Specimens \#6, \#7, and \#8 derived from Krasnoyarsk district, near the Taskino village $\left(53.71^{\circ}\right.$ N, $92.59^{\circ}$ E). Specimen \#9 was collected in Krasnoyarsk district near Novokargino settlement $\left(58.02^{\circ} \mathrm{N}, 92.95^{\circ} \mathrm{E}\right)$. The animals were cared for in accordance with the Guide to the Care and Use of Experimental Animals (Vol. 1, 2nd ed., 1993, and Vol. 2, 1984, available from the Canadian Council on Animal Care (CCAC), 190 O’Connor St, Suite 800, Ottawa, ON K2P 2R3, Canada). Trapping, handling and euthanasia of animals were performed according to the protocols approved by the Animal Care and Use Committees at the Institute of Cytology and Genetics of the Russian Academy of Sciences (IC\&G SB RAS). No additional permits are required for a research on the non-listed species in Russia. The specimens were deposed in the research collections of IC\&G SB RAS.

\section{Metaphase chromosome preparation and specimen karyotyping}

Chromosome preparation was performed from bone marrow and cultured cells according to standard protocol (Baker and Baker 1982). All studied specimens were karyotyped applying inverted DAPI banding and FISH with a set of microdissection derived DNA probes and labeled rDNA as described earlier (Karamysheva et al. 2002). Inverted DAPI-banding is very similar to GTG-banding allowing identification of all chromosome but in this study, we identified only Bs and sex chromosomes. All C-positive regions of As were brightly stained with DAPI: autosomes show large C-positive pericentromeric regions; in the $\mathrm{X}$ - intercalary C-positive region; the $\mathrm{Y}$ shows a distal C-positive region in the long arm. Identification of the Bs was confirmed with FISH with microdissected DNA probes. 


\section{DNA probes and $2 D$ FISH}

DNA probes were generated from microdissection derived DNA libraries, derived from Bs and pericentromeric C-positive regions of medium-size autosomes, followed by DNA labeling by PCR in presence of all 4 dNTPs and biotin-16-dUTP (Sigma-Aldrich), TAMRA-5dUTP (Roche) or Alexa Fluor 488-5-dUTP (Invitrogen) (Karamysheva et al. 2002; Rubtsov et al. 2004). The following whole chromosome paints (WCP) and partial chromosome paints (PCP) were used:

(i) WCP9-B8 derived from the smallest Bs of male \#9 (micro B chromosome);

(ii) PCP11-B2pq derived from the arms of the second in size B of specimen \#11;

(iii) PCP11-AC derived from pericentromeric region of medium-sized autosomes of specimen \#11 (Karamysheva et al. 2002).

2D FISH was performed according to a standard protocol with a salmon sperm DNA as DNA carrier (Rubtsov et al. 2004). WCP-9B8 was Alexa Fluor 488-5-dUTP (green) labeled, PCP11-B2pq was TAMRA-5-dUTP (red) labeled. For simultaneous hybridization of PCP11B2pq and PCP11-AC Alexa Fluor 488-5-dUTP (green) and TAMRA-5-dUTP (red) were used. Chromosomes were counterstained with DAPI (blue).

C-positive regions of the As consisted of homologous clustered repeats (Karamysheva et al. 2002). As consequence, microdissected DNA probe derived from pericentromeric C-positive region of the autosome painted all pericentromeric C-positive regions of autosomes, intercalary C-positive region in the $\mathrm{X}$, and distal $\mathrm{C}$-positive region of the long arm of the $\mathrm{Y}$ (Karamysheva et al. 2002; Rubtsov et al. 2004). The Bs in Ape also consist of C-positive regions containing different clustered repeats (Kartavtseva et al. 2000; Karamysheva et al. 2002, 2010; Trifonov et al. 2002; Rubtsov et al. 2004, 2011). Taken together, data on C-banding of Korean field mouse chromosomes and their painting with PCP11-AC, PCP11-B2pq and WCP9-B8 allowed 
considering the PCP11-AC+/WCP9-B8- and the PCP11-B2pq region as typical C-positive heterochromatic chromosome regions enriched with different repeats. The PCP11-AC-/WCP9B8+ regions are also enriched with repeats but they are undercondensed in mitosis and cannot be revealed with C-banding or even with routine Giemsa staining (Rubtsov et al. 2004). They might not be named C-positive regions but according to high enrichment with repeats they might be probably referred to heterochromatic chromosome regions.

The DNA probe used for detection of $18 \mathrm{~S}$ rDNA clusters (rDNA probe) contained a 3.2$\mathrm{kb}$ fragment of human 18S rDNA in vector pHr13 (Malygin et al. 1992). It was labeled with biotin-16-dUTP by standard nick translation Kit (Invitrogen).

\section{Cell cultures}

Cell cultures were established from breast cartilage or tail intervertebral cartilage of specimens \#10 and \#6 by standard techniques (Sambrook and Pollack 1974). In brief: cartilages were dissected into small pieces and placed in serum-free DMEM medium (GIBCO) with following short-term (10-15 minutes) treatment with collagenase mix (Sigma Aldrich, C5138, $0.5 \mathrm{mg} / \mathrm{ml}$ ) at $37^{\circ} \mathrm{C}$ (La Salle et al. 2009). Then small pieces of tissue and single cells were separated with centrifugation at $1000 \mathrm{rpm}$, washed with serum-free DMEM medium, placed into cell-culture flasks with DMEM medium containing $8 \%$ of fetal calf serum (HyClone), and incubated for $2-3$ days at $5 \% \mathrm{CO}_{2}$ and $37^{\circ} \mathrm{C}$. The cell debris was washed out. Cells attached to the surface of culture flasks were trypsinized and replaced into new cell-culture flasks. The number of cell passages did not exceed eight.

\section{Preparation of 3D-preserved interphase nuclei for FISH analysis}

Fibroblasts cultivated in vitro were seeded onto $60 \times 24 \mathrm{~mm}$ coverslips in quadriperm plates in DMEM medium supplemented with $10 \%$ fetal calf serum (FCS) in the $\mathrm{CO}_{2}$ incubator $\left(5 \% \mathrm{CO}_{2}\right.$ and $\left.37^{\circ} \mathrm{C}\right)$ and cultivated until a subconfluent monolayer was formed. Then coverslips 
were briefly rinsed in PBS, fixed at room temperature in freshly prepared 4\% paraformaldehyde for 10 min. Permeabilization of nuclei was performed with $0.5 \%$ Triton X-100 in PBS for 20 min, 20\% glycerol in PBS (30 min), repeated freezing/thawing in liquid nitrogen four times, and incubation in $0.1 \mathrm{~mol} / 1 \mathrm{HCl}(10 \mathrm{~min})$ as described (Solovei et al. 2002b). A little modification included RNase treatment $(100 \mu \mathrm{g} / \mathrm{ml}$ in $2 \times \mathrm{SSC})$ at $37^{\circ} \mathrm{C}$ for $60 \mathrm{~min}$. Procedures were carried out without drying of the cells. Slides were kept at $4^{\circ} \mathrm{C}$ in $50 \%$ formamide $/ 2 \times \mathrm{SSC}$ until hybridization.

Spermatocytes of specimens \#1 to \#9 were isolated and detunicated as described (La Salle et al. 2009) for the preparation of 3D preserved nuclei. Testes were disrupted mechanically with needles to release cells in culture media. Testicular cells from suspensions enriched with pachytene spermatocytes were attached to polylysine coated slides with incubation in DMEM medium supplemented with $10 \%$ FCS in a humidity chamber for several hours at $37^{\circ} \mathrm{C}$ and permeabilized according to standard protocol (Solovei et al. 2002b). To determine the meiotic stage of isolated cells immunostaining with a polyclonal rabbit anti-SCP3 and anti-SCP1 (Abcam) antiserum was performed as described by Scherthan et al (2000).

\section{D fluorescence in situ hybridization (3D FISH)}

3D FISH was performed as described (Solovei et al. 2002a, 2002b). PCP11-AC was labeled with biotin and detected by Streptavidin - Cy5 (Invitrogen, yellow). PCP11-B2pq and WCP9-B8 were labeled with TAMRA-5-dUTP (Roche, red) and Alexa Fluor 488-5-dUTP (Invitrogen, green), respectively. The probes were dissolved in hybridization mixture (50\% formamide, $10 \%$ dextran sulfate, $2 \times \mathrm{SSC}, 0.01 \% \mathrm{NP}-40$ ), loaded on the slide with pretreated cells, covered with coverslip $(24 \times 24 \mathrm{~mm})$, and sealed with rubber cement. The DNA of nucleus and probes was denatured on the hot-block of Thermomixer comfort, Eppendorf at $73^{\circ} \mathrm{C}$ for 5 min. Hybridization was performed for 2 days in humid boxes at $37^{\circ} \mathrm{C}$. Post-hybridization 
washing was performed in $0.1 \times \mathrm{SSC}$ at $60^{\circ} \mathrm{C}$ and $4 \mathrm{SSC} / 0.1 \% \mathrm{NP}-40$ solutions at $45^{\circ} \mathrm{C}$ for 5 min. Then nuclear DNA was counterstained with DAPI and mounted in Invitrogen Prolong Gold Antifade.

\section{Detection of the C-positive regions of the $A$ and $B$ chromosome specific regions by $3 D$ FISH} "PCPCA+, WCP9B8+, PCP11B2pq-" compartments of nuclei were considered as Cpositive regions of the As and regions of the Bs enriched with pericentromeric repeats. "PCPCA, WCP9B8-, PCP11B2pq+" compartments were considered as B-chromosome regions enriched with B1 repeats. Regions of the Bs consisted of low condensed chromatin in mitosis could not be detected in nuclei. No "PCPCA-, WCP9B8+, PCP11B2pq-" was detected. Probably, they were too small, compact and located close to pericentromeric chromosomal regions or to PCP11-AC+, WCP9-B8+, and PCP11-B2pq- regions of Bs. As a consequence, the voxels corresponding to location of PCP11-AC-, WCP9-B8+, and PCP11-B2pq- region were also included in PCP11$\mathrm{AC}+$ or $\mathrm{PCP} 11-\mathrm{B} 2 \mathrm{pq}+$ regions. As a result, they were classified as regions enriched with pericentromeric repeats or the regions on the borderline of PCP11-AC+, WCP9-B8+ and PCP11B2pq- regions.

\section{Synaptonemal Complex (SC) spreading, immunostaining, microscopy and imaging}

Preparation of pachytene chromosomes and their analysis was performed as described earlier (Torgasheva et al. 2013). For visualization of the synaptonemal complex (SC), immunostaining with rabbit polyclonal antibodies against proteins of the central SC element SYCP1 and lateral SC element SYCP3 (Abcam) was performed as described by Scherthan et al. (2000). For visualization of the meiotic silencing of unsynapsed chromatin, rabbit polyclonal antibody against phosphorylated histone H2A.X ( $\gamma$ H2A.X, Abcam) was used. Secondary goat anti-rabbit antibodies conjugated to Cy3, FITC (Jackson ImmunoResearch), and Alexa450 (Invitrogen) were used. 


\section{Microscopy}

2D-microscopy was carried out with an Axioskop 2 Plus microscope (Zeiss) equipped with a CCD camera and filter sets (ZEISS \#49, \#10, \#20). ISIS5 image-processing package of MetaSystems GmbH was used to capture and process microscopic images. Confocal microscopy was performed using LSM510META confocal system (ZEISS) with an Diode 405nm, Argon $488 \mathrm{~nm}$, Helium/Neon $543 \mathrm{~nm}$ and 633nm laser lines; filters BP 445-450, BP 420-480 IR, LP 650, and BP 505-570 equipped on AxioObserver Z.1 microscope ( $\times 63$ oil immersion objective with a numerical aperture of 1.4). Thickness of optical slice was $0.6 \mu \mathrm{m}$. The images were analyzed using LSM Image Browser (Zeiss) and ZEN 2009 software.

Microscopy was performed in the Microscopic Centre of the Institute of Cytology and Genetics SB RAS, Novosibirsk, Russia.

\section{Estimation of the amount of B chromosome DNA in studied specimens}

To estimate the amount of B chromosome DNA in individual specimens, morphometry of all chromosomes in 20 or more metaphases was done. For the measurement a special option of AxioVision software (Zeiss) was applied. For the estimation of the amount of B chromosome DNA, the ratio of the total length of all Bs in metaphase spread to the total length of the As was calculated. The mean value and standard deviation was calculated for each specimen. This approach could lead to underestimation of the B chromosome amount in specimen genomes due to the higher condensation of heterochromatic Bs in comparison with the euchromatic part of the As. We should also note that undercondensed regions of the Bs avoided the detection and measurements, decreasing the mean value of estimation of additional B chromosome material.

\section{Scoring of chromocenters}

Galleries of serial optical sections and orthogonal projections were used for tracing the territories of B-chromosome and chromocenters. Positions of specific signals in the nuclei were classified similarly to the method described by Williams et al. (2002) for classification of the 
gene positions in relation to the chromosome territory. The positions of territories including the Bs and chromocenters were considered as peripheral when their signals were in contact with the edge of the nucleus defined by DAPI staining. The positions of the Bs territories were considered as nucleolus associated when their signals were in contact with the nucleolus edge. All other signals located into the nucleus were scored as internal.

\section{Evaluation of the possible random disposition of PCP11-B2pq+ regions in PCP11-AC+}

\section{compartment}

A computing experiment was carried out to simulate random distribution of the $\mathrm{B}$ chromosomes containing PCP11-B2pq+ regions among heterochromatic compartments of interphase nucleus derived from C-positive regions of A chromosomes. The basic part of this experiment was the simulation of random distribution of the Bs among PCP11-AC+ compartments. The actual number of PCP11-AC+ compartments was determined in FISH experiments in all nuclei. In the specimen \#10 the number of Bs with PCP11-B2pq+ regions was 8, while PCP11-AC+ compartments in nuclei varied from 6 to 20. The number of studied nuclei of diploid fibroblasts of this specimen was 20. In computing experiment for each nucleus, the Bs with PCP11-B2pq+ regions were randomly referred to the one of heterochromatic compartments. If one or more Bs with $\mathrm{PCP} 11-\mathrm{B} 2 \mathrm{pq}+$ regions appeared to be in one $\mathrm{PCP} 11-\mathrm{AC}+$ compartment we considered them producing one signal. The number of the "PCP11-B2pq+ signals" was scored for each nucleus and this procedure was repeated $10^{5}$ times.

The same computing experiment was carried out for the specimen \#6 as well. For this specimen the number of Bs with PCP11-B2pq+ regions was 4 and PCP11-AC+ compartments varied from 11 to 26 . The number of studied nuclei of fibroblasts of this specimen was 18 .

Distribution of PCP11-B2pq $+\mathrm{B}$ chromosomes obtained in computer simulation and observed in experiments was compared with a Mann-Whitney test. 


\section{Results}

\section{Karyotyping of the specimens}

Karyotypes of all specimens were determined using DAPI-banding and 2D-FISH applying DNA probes derived from microdissection and labeled rDNA (Fig. 1, Table 1). A standard set of As with 46 autosomes plus sex chromosomes (X and Y) was detected in all animals. The number of Bs varied from 3 to 19. The observed B size varied from dot-like to a size comparable with the largest autosome pair (Table 1, Fig. 1). Dot-like Bs did not contain visible arms. They were described earlier and named micro-Bs (Rubtsov et al. 2004). Bs with at least one visible arm after DAPI staining were considered macro-Bs (Rubtsov et al. 2004, 2015).

\section{Estimation of the ratio of the cumulative length of the Bs to the cumulative length of the A chromosomes}

The presence of Bs increased the number of centromeres and the heterochromatic amount of the nucleus. The variation in the number and size of Bs led to the variation in the amount of DNA added to the basic genome. The amount of additional DNA is given as the ratio of the cumulative length of all Bs to the cumulative length of all As in a metaphase plate. Morphometry of all chromosomes was performed in 20 or more metaphase spreads. Obtained results are summarized in the Table 1 . In analyzed specimens, the ratio B/A varied between $0.04 \pm 0.01$ to $0.32 \pm 0.09$, suggesting that amount of the B DNA varied between 4 to $32 \%$ of the diploid genome consisted of only As. The mean values were probably underestimated due to high level of chromatin condensation in C-positive regions and avoiding visualization of low condensed regions in some Bs.

Painting of As produced by FISH using DNA probes derived from microdissection was similar to the one reported earlier (Karamysheva et al. 2002; Rubtsov et al. 2004, 2015). PCP11$\mathrm{AC}$ probe painted the pericentromeric regions of all autosomes, an intercalary heterochromatic 
region in the $\mathrm{X}$, and the distal region of the long arm of the $\mathrm{Y}$. In the As, WCP9-B8 painted the same regions as PCP11-AC but slightly less intensive. PCP11-B2pq painted slightly most Cnegative regions of the As (Fig. 1a, b, c) and slightly more intensive proximal C-negative regions of the sex chromosomes.

All Bs analyzed in the studied specimens were characterized by FISH with WCP9-B8, PCP11-B2pq, and PCP11-AC. The B results as well as the morphological description including the size and number of the arms are shown in Figure 1 and Table 1 . In all micro-Bs the small pericentromeric regions were painted with PCP11-AC and WCP9-B8. The regions hybridizing with these probes were normally condensed and stained both with DAPI and Giemsa (Carvalho et al. 2001; Karamysheva et al. 2002). Except for small pericentromeric regions, micro-Bs consisted of chromatin characterized by a low level of condensation in metaphase plates. Chromatin of the latter regions formed a very thin layer around the condensed pericentromeric region in metaphase plates and seemed invisible after DAPI or Giemsa staining (Karamysheva et al. 2002; Rubtsov et al. 2004). At the same time, these regions showed strong signals for WCP9B8 (Fig. 1b). This FISH pattern was identical to the one described for micro-Bs earlier (Karamysheva et al. 2002; Rubtsov et al. 2004). In this study, micro-Bs were observed in karyotypes of four specimens (Fig. 1d, Table 1). The number of micro-Bs varied from 3 in specimen \# 9 to 15 in specimen \#8.

All macro-Bs found in the specimens involved in the study contained pericentromeric regions painted with PCP11-AC and WCP9-B8. The arms of the Bs contained the regions painted with PCP11-B2pq (regions enriched with B1 repeats) (Rubtsov et al. 2004) or with PCP11-AC and WCP9-B8. The only exception was the largest B in specimen \#5 (Fig. 1a, d). In its long arm small region was not painted with microdissected probes at all (Fig. 1a). The largest macro-Bs in specimens \#1, \#2, \#4, \#7 and \#10 contained low condensed regions. These regions 
could not be revealed after DAPI staining and were painted exclusively by WCP9-B8 probe derived from the micro-Bs (Fig. 1c, d).

FISH with DNA probes derived from microdissection allowed us to identify three types of B-chromosome-regions: (i) regions enriched with pericentromeric repeats (PCP11-AC+, WCP9-B8+, PCP11-B2pq-); (ii) regions enriched with B1 repeats (PCP11-AC-, WCP9-B8-, PCP11-B2pq +); and (iii) regions enriched with B2 repeats (PCP11-AC-, WCP9-B8+, PCP11$\mathrm{B} 2 \mathrm{pq}-)$.

Clusters of rDNA were earlier identified in some Bs of previously studied Ape specimens (Rubtsov et al. 2004) but no such rDNA clusters were identified in Bs in specimens of this study. FISH with labeled rDNA showed clusters of rDNA only in the subtelomeric regions of two pairs of As.

\section{Detection of B chromosome specific regions by 3 D FISH.}

In interphase nuclei C-positive regions of the As and regions of the Bs enriched with pericentromeric repeats were characterized by identical combination of FISH signal "PCPCA+, WCP9B8+, PCP11B2pq-". All three probes PCP11-AC, WCP9-B8, and PCP11-B2pq were used in two different color combinations. Since the As and Bs could not be distinguished in interphase, the number of chromocenters labeled as "PCP11-AC+, WCP9-B8+, PCP11-B2pq-“" were scored in the analyzed nuclei.

Territories of B-chromosome regions enriched with B1 repeats could be reliably detected as a compartment of interphase nucleus labeled as "PCP11-AC-, WCP9-B8-, PCP11-B2pq+" (Fig. 2a, b). B1-specific probe PCP11-B2pq+also slightly painted C-negative regions of As at metaphase, though in interphase the signals at these regions were close to background noise. Some micro-Bs and the ends of macro-Bs contained regions of low condensed chromatin that were labelled only with WCP9-B8+ probe but not with PCP11-AC- and PCP11-B2pq- (Fig. 1c; 
Fig.2d, e, green). "PCP11-AC-, WCP9-B8+ and PCP11-B2pq-“ compartments were also observed in the nuclei of studied specimens (Fig. 3). In the nuclei, the C-positive regions of the As could not be distinguished from the regions of the Bs enriched with B2 repeats because all of them were "PCP11-AC+, WCP9-B8+, PCP11-B2pq-" (Fig.2, 3).

2D-FISH and 3D-FISH with PCP11-AC probe produced more intense signals than with WCP9-B8 probe, and allowed to detect smaller regions enriched with pericentromeric repeats in interphase nuclei. For this reason for calculation of the number of signals in the latter region, we used only PCP11-AC signals.

\section{$3 D$ organization of fibroblast nuclei}

The spatial organization of interphase nuclei in fibroblasts was characterized by Bchromosome location in nuclear periphery, in compartments together with C-positive regions of the As (Fig.4). In specimen \#10, FISH with PCP11-AC labeled, at least, 56 regions in metaphase chromosomes. Forty-eight of them belonged to As and 8 to macro-Bs. In interphase nuclei, the mean value of separated compartments labeled with PCP11-AC was $10.55 \pm 0.84$. Metaphase chromosomes of specimen \#6 contained 66 PCP11-AC+ regions; 18 of them belonged to Bs. Four of the Bs were macro-Bs and 14 were micro-Bs. Together with As they formed compartments in the nuclei of cultured fibroblasts 16.67 \pm 1.12 PCP11-AC+ (Fig.4).

PCP11-B2pq+ regions were present in the Bs of both specimens. Four and eight PCP11$\mathrm{B} 2 \mathrm{pq}+$ regions were detected in the Bs, respectively, in specimens \#6 and \#10. In interphase nuclei, all PCP11-B2pq+ compartments were in contact with large PCP11-AC+ compartments. The mean values of PCP11-B2pq+ signals in interphase nuclei were $2.11 \pm 0.21$ for specimen \#6 and $7.17 \pm 0.31$ for specimen $\# 10$. We conducted computer simulation of random distribution of PCP11-B2pq+ compartments among PCP11-AC+ compartments. If several PCP11-B2pq+ regions were united into the same compartment, we considered them as producing one signal. In 
computer simulation, the numbers of studied nuclei were equal to the numbers of nuclei studied in the present study. Simulation was performed 100,000 times for each specimen and the distribution of mean values was calculated. The number of registered PCP11-B2pq+ compartments calculated in experiments differed from the ones obtained in the computer simulation. For the specimen \#6 it was lower whereas for the specimen \#10 it was higher than the number obtained in computer simulation. In both cases, the difference was significant and indicated a nonrandom distribution of the B-chromosome-PCP11-B2pq + regions in PCP11-AC+ compartments of the interphase nucleus.

\section{$3 D$ organization of spermatocyte nuclei}

For analysis of spermatocyte nucleus organization, spermatocytes at pachytene stage were selected. They were marked with SYCP3 antibodies against SC (Fig. 5). At this stage, the amount of DNA is $4 \mathrm{C}$ and the architecture of the nuclei is reorganized due to the chromosome pairing and bivalent formation. Two homologous autosomes form each bivalent. Together with the sex chromosomes, each cell contained $25 \mathrm{C}$-positive PCP11-AC+ regions derived from Achromosome-bivalents, i.e., 23 pericentromeric regions of autosomal bivalents, intercalary Cpositive region in the $\mathrm{X}$, subtelomeric $\mathrm{C}$-positive region of $\mathrm{Yq}$, and additional $\mathrm{PCP} 11-\mathrm{AC}+$ regions derived from the Bs. The nuclei were sphere-shaped with a minimal possible ratio between the surface area and the nucleus volume. PCP11-AC+ compartments were localized mostly in the periphery of spermatocyte nuclei. In six specimens, their number varied from $6.1 \pm$ 0.3 to $9.9 \pm 0.8$ (Table 1$)$.

As mentioned above 3D FISH with PCP11-AC could not differentiate PCP11-AC+ regions of As and Bs whereas 3D FISH with PCP11-B2pq detected reliably the compartments formed with PCP11-B2pq + regions of macro-Bs. Their mean number in spermatocyte nuclei in the studied specimens varied from 1.2 in to 2.89 . The lowest number 1.2 was detected in the 
spermatocyte nuclei of specimen \#9. The Bs of this specimen contained only two PCP11-B2pq+ regions. Furthermore, one of them was very small and could have been missed in a part of the analyzed nuclei. In spermatocyte nuclei of other specimens the number of PCP11-B2pq+ compartments appears to be in a narrow interval, between 2.03 to 2.89 in spite of the variation of the PCP11-B2pq + region numbers in metaphase Bs within a range from 2 to 12 . It should be also noted that in most pachytene nuclei, at least, part of PCP11-B2pq+ regions were located very close to a sex vesicle formed by XY bivalent, which was identified with SYCP3 antibodies and DAPI staining (Fig. 5).

\section{D study of pachytene chromosomes}

The meiotic behavior of $\mathrm{Bs}$ at pachytene was analyzed by immunostaining with antibodies against SYCP1 and SYCP3. Unrepaired double-strand breaks and meiotic sex chromosome inactivation (MSCI) was detected with antibodies against phosphorylated histone H2A.X ( $\gamma \mathrm{H} 2 \mathrm{~A} . \mathrm{X})$. At pachytene, autosomes formed 23 bivalents. The cells with completely paired autosomes were involved in the further analysis. The Bs formed in cell from 3 to 18 SCs. They were of three types: synapsed bivalents, univalents, and univalents showing SCP1 immunostaining (univalents containing foldback structure) (Fig.5). No multivalent formed by the Bs was registered.

Pachytene stage (early, mid, and late) was determined according to degree of sex chromosome conjugation. Cells containing unpaired $\mathrm{X}$ and $\mathrm{Y}$ were considered as early pachytene cells. Cells containing paired $\mathrm{X}$ and $\mathrm{Y}$, showing clear immunostaining signal of SYCP1 in pseudoautosomal region, and $\gamma \mathrm{H} 2 \mathrm{~A} . \mathrm{X}$ immunostaining over unsynapsed parts were referred to mid pachytene cells. Cells containing compacted $\mathrm{X}$ and $\mathrm{Y}$ heavily labeled with $\gamma \mathrm{H} 2 \mathrm{~A} . \mathrm{X}$ antibodies were referred to late pachytene. 
The fraction of bivalents formed by the Bs increased from $2 \%$ to $12 \%$ from early to late pachytene. Some univalents that failed to pair to each other, paired to themselves in a foldback manner. Central SC element in such elements appeared later and disappeared earlier than in the A-chromosomes.

At early pachytene, $58 \%$ of SCs involving Bs of all types were labeled with $\gamma \mathrm{H} 2 \mathrm{~A} . \mathrm{X}$ antibodies (Fig. 5). At late pachytene, their portion decreased to $20 \%$. In univalents, $\gamma \mathrm{H} 2 \mathrm{~A} . \mathrm{X}$ signal remained visible when it disappeared from bivalents. Spermatocyte spreading on the slide disrupted their spatial organization. Nevertheless, even on the spreads, the Bs tended to be located close to sex body forming joint cloud of $\gamma \mathrm{H} 2 \mathrm{~A} . \mathrm{X}$ staining. The number of elements associated with XY bivalent increased through pachytene stages. B univalents appeared to be involved in the association with the $\mathrm{XY}$ bivalent more frequently than the $\mathrm{B}$ bivalents. 


\section{Discussion}

\section{The volume of C-positive heterochromatic regions affects 3D-organization of the nucleus}

Despite the existence of numerous studies that showed that heterochromatin and centromeres are predominantly located at the periphery of interphase nuclei (Weierich et al. 2003; Cremer and Cremer 2010; Manvelyan et al., 2008), studies on the influence of the different amount of these heterochromatic nuclear components are not available yet. The Korean field mouse is a uniquely suitable organism for studying the influence of additional heterochromatin and an increased centromere number on the spatial organization of the interphase nucleus due to a highly variable number of Bs in this species. In the present study, the number of additional centromeres owing to Bs ranged from 3 to 19. The estimation of additional chromatin showed a variation from 4 to $32 \%$ of the Ape diploid genome consisted of only the A chromosomes. Interestingly, despite of such variations, up to now, there is no evidence for a Bchromosome influence on specimen fitness in Ape.

This study showed that the principle of 3D-organization of the nucleus does not change even in the presence of multiple Bs. In all studied specimens, compartments of chromosomal regions enriched with repetitive DNA were localized mainly in the nuclear periphery. It was also observed that the increased number of centromeres and pericentromeric clusters of repetitive DNA led to the increased number of the compartments including the chromosomal regions enriched with repetitive DNA. The increased number of centromeres and pericentromeric regions provided probably additional initiating points and extra material for formation of the territories enriched with repetitive DNA. Probably, enlargement of genome size led to the increase of the nuclear volume including nuclear surface and consequently gave more space in nuclear periphery for separated pericentromeric DNA compartments. 


\section{Nonrandom distribution of Bs in fibroblast nuclei}

3D organization of the nucleus is an important feature for normal genome functioning. In the nuclei of Ape cells C-positive regions formed large territories located in the nuclear periphery. However, in fibroblasts derived from specimen \#10, the distribution of Bs containing PCP11$\mathrm{B} 2 \mathrm{pq}+$ regions in $\mathrm{PCP} 11-\mathrm{AC}+$ territories was not random: in case of a random distribution, according to computer simulation, an expected mean value of the number of PCP11-B2pq signals should be $5.34 \pm 0.17$, whereas registered number of PCP11-B2pq signals in PCP11-AC+ compartments was $7.17 \pm 0.31$. Furthermore, this observed mean value was probably underestimated because in some nuclei the small Bs might escape detection decreasing the observed mean value of compartments showing PCP11-B2pq+ signals. In nuclei of fibroblasts derived from specimen \#6 all four macro-Bs were small and one of them contained a very small PCP11B2pq + region; similarly, in some nuclei its signal could not be registered. Thus, the experimental mean value was underestimated in all probability, up to inverse ratio of expected and observed numbers of PCP11-AC+/ PCP11-B2pq+ compartments. The expected mean value was 3.6 \pm 0.14 whereas the observed mean value was $2.11 \pm 0.21$. We suggest that in nuclei of fibroblasts derived from specimen \#6 macro-Bs also showed the trend to be located in separated PCP11-AC+ compartments. However, explanation of this phenomenon requires further investigation. We would like to note that large and medium-sized macro-Bs are significantly larger then C-positive regions of As in interphase. The combination of some C-positive regions of As with two large or medium-sized macro-Bs could produce too large PCP11-AC+ compartments that consequently disturbed spatial organization of the nucleus. This suggestion is in concordance with the calculated number of PCP11-AC+ / PCP11-B2pq+ compartments in nuclei of the studied fibroblasts. We should also take into account that the morphology of nucleus shapes of cells derived from different and even the same tissue is variable. As a result, 
the ratio between the area of the nuclear periphery and the volume of the whole nucleus is also variable and spatial organization of the nucleus should be adapted to these variations.

Genomes of fibroblasts derived from both specimens were characterized with similar volumes of additional DNA comprised in Bs, but the number and types of these Bs were different. In contrast to eight macro-Bs in specimen \#10, the karyotype of specimen \#6 included four macro-Bs and 14 micro-Bs. The ratio of active centromeres in specimens \#6 and \#10 was 1.18 whereas the ratio of PCP11-AC+ compartments in nuclei of their fibroblasts was 1.58 . An increase of centromere numbers led to formation of higher numbers of C-positive compartments, and probably decreased their average size.

\section{Changes in heterochromatin volume and amount of repetitive DNA does not modify the nuclear position of chromosomes}

Despite variations in heterochromatin amount, number of active centromeres and change of $3 \mathrm{D}$ architecture of interphase nucleus, there is no visible impact of Bs on animal fitness for the Korean field mouse. Earlier no correlation was found between frequencies of the Bs and the level of protein or gene polymorphism. Furthermore, no measurable effect of the Bs on overall genetic variability was revealed and no unambiguous interrelationship was found between the frequency of Bs and various biological and/or ecological variables (Zima and Macholan 1995; Wójcik et al. 2004). We suppose that the critical point in spatial organization of the nucleus is the optimal ratio of nuclear periphery and inner compartments of the nucleus. This optimal value is dependent on the heterochromatin volume and the number of active centromeres. The value of this ratio may vary with nuclear morphology variation. In general, the morphology of the cells and nuclei is very variable. The nuclei of the cells forming various tissues show large difference in size and morphology. Depending on the cell type, the form of nuclei can vary from spherical to flat and elongated or even segmented. We suppose that the change of parameters of the 
nuclear morphology allows optimizing 3D nuclear organization. Taking into account, that recovering nuclear membrane starts partly from the points associated with heterochromatic regions of chromosomes we suggest that the increase of the heterochromatin volume in the genome of a specimen leads to the increase of the surface of the nuclear membrane. Hence, additional macro-Bs in the Korean field mouse consisting of repetitive DNA could automatically adjust nuclear morphology for increased volume of heterochromatin in individual genomes. Probably the same adaptation of nuclear morphology took place during evolution in many other mammalian species, that was accompanied by the generation of new heterochromatic regions (Hattori 2005). Flexibility of nuclear morphology is an important mechanism of adaptation to the changes of the C-heterochromatin volume derived from enlargement of existing C-positive regions and formation of the new ones observed in the evolution of many taxa (Nystedt et al. 2013). Actually, comparative cytogenetics revealed many examples of significant variation of volume of C-heterochromatin even at population level (Rubtsov et al. 2011). Variation of Cpositive regions are also well known in human chromosomes (Liehr 2014).

\section{The chromosome size-dependent theory and the B in Korean field mouse}

In the study on three-dimensional positioning of B chromosomes in fibroblast nuclei of the red fox and the Chinese raccoon dog (Kociucka et al. 2013) a dominant mode of the small Bs of the red fox in the interior of the nucleus was revealed, whereas the medium-sized Bs of the Chinese raccoon dog were observed in the peripheral area of the nucleus as well as in intermediate and interior locations. These data were in agreement with the chromosome sizedependent theory (Kociucka et al. 2013). In the nuclei of Korean field mouse all Bs, irrespective of their size, were located on nuclear periphery in common compartments with C-positive regions of A chromosomes. We suppose that at least for the Bs of Korean field mouse their DNA content is more important parameter determining the B location inside the nucleus.

\section{Co-localization of XY-bivalent and Bs in spermatocytes}


In contrast to fibroblast, in spermatocytes we paid attention to a tendency for co-localization of Bs with each other. The parts of unpaired Bs, especially lacking SCP1 signal, were associated with the sex body and formed a compartment of unsynapsed chromatin together with XYbivalent. Other unpaired Bs could form another compartment of unsynapsed chromatin (Fig. 5). This finding is in an accordance with the results of the previous study on B-chromosome behavior in meiotic prophase I of Ape (Kolomiets et al. 1988). At pachytene, we also found different timing of $\gamma \mathrm{H} 2 \mathrm{~A} . \mathrm{X}$ labeling in A and Bs. Some Bs were labelled with $\gamma \mathrm{H} 2 \mathrm{~A} . \mathrm{X}$ whereas in As double-strand breaks were repaired and there was no $\gamma \mathrm{H} 2 \mathrm{~A} . \mathrm{X}$ labelling. It is known that phosphorylation of the histone H2A.X $(\gamma \mathrm{H} 2 \mathrm{~A} . \mathrm{X})$ is involved in meiotic sex chromosome inactivation (MSCI). The similar mechanism provides transcriptional silencing of unpaired chromatin (MSUC) in autosomes that may activate pachytene checkpoint and lead to apoptosis (Turner et al. 2005; Baarends et al. 2005). However, it was shown that limited degree of asynapsis could be ignored by pachytene checkpoint mechanisms in mice and humans (Sciurano et al. 2007; Burgoyne et al. 2009; Manterola et al. 2009). It is possible that pairing of Bs with each other or with themselves and their inclusion into transcriptionally silenced sex body compound can help to avoid apoptosis normally induced by pachytene checkpoint mechanisms.

In conclusion, an additional volume of heterochromatic regions of chromosomes and extra centromeres modify 3D architecture of interphase nuclei in Ape. In meiosis, the location of Bs appeared to be not random. Unpaired Bs show a tendency to form a common compartment with unpaired part of the XY-bivalent.

\section{Acknowledgements}

The authors thank Dr Polina Perelman ((Institute of Molecular and Cellular Biology, Novosibirsk, Russia) and Dr.Snejana Grozeva (Institute of Biodiversity and Ecosystem Research 
Bulgarian Academy of Sciences Sofia, Bulgaria, Department of Zoology), who have kindly read the manuscript and made valuable suggestions. We thank Michail N. Bochkarev (Institute of Cytology and Genetics, Siberian Branch of Russian Academy of Sciences) and Yurii M. Borissov (Severtsov Institute of Ecology and Evolution of the Russian Academy of Sciences) for giving us the animals. Dr. Nadezhda M. Belonogova (Institute of Cytology and Genetics, Siberian Branch of Russian Academy of Sciences) for help with statistic date. Dr. Maria Prokhorovich for help with cell culter. This work was partially supported by the Federal Agency of Scientific Organizations via the Institute of Cytology and Genetics (project \# 0324-20160003). 


\section{References}

Alcobia, I., Dila, R., and Parreira, L. 2000. Spatial associations of centromeres in the nuclei of hematopoietic cells : evidence for cell-type-specific organizational patterns. Blood. 95(5): $1608-1615$.

Baarends, W.M., Wassenaar, E., van der Laan, R., Hoogerbrugge, J., Sleddens-Linkels, E., Hoeijmakers, J.H.J., de Boer, P., and Grootegoed, J.A. 2005. Silencing of unpaired chromatin and histone H2A ubiquitination in mammalian meiosis. Mol. Cell. Biol. 25(3): 1041-1053. doi:10.1128/MCB.25.3.1041-1053.2005.

Baker, I., and Baker, H.G. 1982. Some chemical constituents of floral nectars of Erythrina in relation to pollinators and systematics. Allertonia. 3: 25-37.

Bickmore, W.A. 2013. The Spatial Organization of the Human Genome. Annu. Rev. Genomics Hum. Genet. 14: 67-84. doi:10.1146/annurev-genom-091212-153515.

Boyle, S., Gilchrist, S., Bridger, J.M., Mahy, N.L., Ellis, J.A, and Bickmore, W.A. 2001. The spatial organization of human chromosomes within the nuclei of normal and emerin-mutant cells. Hum. Mol. Genet. 10(3): 211-219. doi:10.1093/hmg/10.3.211.

Burgoyne, P.S., Mahadevaiah, S.K., and Turner, J.M.A. 2009. The consequences of asynapsis for mammalian meiosis. Nat Rev Genet. 10(3): 207-216. doi:10.1038/nrg2505.

Carvalho, C., Pereira, H.M., Ferreira, J., Pina, C., Mendonça, D., Rosa, A.C., and CarmoFonseca, M. 2001. Chromosomal G-dark bands determine the spatial organization of centromeric heterochromatin in the nucleus. Mol. Biol. Cell. 12(11): 3563-3572. doi:10.1091/mbc.12.11.3563.

Cremer, T., and Cremer, C. 2001. Chromosome territories, nuclear architecture and gene regulation in mammalian cells. Nat. Rev. Genet. 2(4): 292-301. doi:10.1038/35066075.

Cremer, T., and Cremer, M. 2010. Chromosome territories. Cold Spring Harbor Laboratory Press. 2(3): a003889. doi:10.1101/cshperspect.a003889. 
Dostie, J., and Bickmore, W.A. 2012. Chromosome organization in the nucleus - charting new territory across the Hi-Cs. Current opinion in genetics \& development. 22(2): 125-131. doi:10.1016/j.gde.2011.12.006.

Hattori, M. 2005. Finishing the euchromatic sequence of the human genome. Tanpakushitsu Kakusan Koso. 50(2): 162-168. doi:10.1038/nature03001.

Karamysheva, T.V., Andreenkova, O.V., Bochkaerev, M.N., Borissov, Y.M., Bogdanchikova, N., Borodin, P.M., and Rubtsov, N.B. 2002. B chromosomes of Korean field mouse Apodemus peninsulae (Rodentia, Murinae) analysed by microdissection and FISH. Cytogenet Genome Res 96(1-4): 154-160. doi:10.1159/000063027.

Karamysheva, T.V., Bogdanov, A. S., Kartavtseva, I.V., Likhoshvay, T. V., Bochkarev, M.N., Kolcheva, N.E., Marochkina, V.V., and Rubtsov, N.B. 2010. Comparative FISH analysis of C-positive blocks of centromeric chromosomal regions of pygmy wood mice Sylvaemus uralensis (Rodentia, Muridae). Russ. J. Genet. 46(6): 712-724. doi:10.1134/S1022795410060128.

Karamysheva, T., Kosyakova, N., Guediche, N., and Liehr, T. 2015. Small supernumerary marker chromosomes and the nuclear architecture of sperm - a study in a fertile and an infertile brother. Syst. Biol. Reprod. Med. 61(1): 32-36. doi:10.3109/19396368.2014.979956.

Kartavtseva, I. 2002. Karyosystematics of wood and field mice (Rodentia: Muridae). Russian Academy of Sciences Far Eastern Branch, Dalnauka, Vladivostok.

Kartavtseva, I. V, Rosliki, G.V., Yu Amachaeva, E., Sawaguchi, S., and Obara, Y. 2000. The Bchromosome system of the peninsutae in the Russian Far East Korean field mouse Apodemus. Chromosom. Sience 4(1): 21-29.

Klein, E., Manvelyan, M., Simonyan, I., Hamid, A.B., Guilherme, R., Liehr, T., and Karamysheva, T. 2012. Centromeric association of small supernumerary marker 
chromosomes with their sister-chromosomes detected by three dimensional molecular cytogenetics. Mol. Cytogenet. 5(1): 15. doi:10.1186/1755-8166-5-15.

Kociucka, B., Sosnowski, J., Kubiak, A., Nowak, A., Pawlak, P., and Szczerbal, I. 2013. Threedimensional positioning of $\mathrm{B}$ chromosomes in fibroblast nuclei of the red fox and the chinese raccoon dog. Cytogenet. Genome Res. 139(4): 243-9. doi:10.1159/000348434.

Kolomiets, O.L., Borbiev, T.E., Safronova, L.D., Borisov, Y.M., and Bogdanov, Y.F. 1988. Synaptonemal complex analysis of B-chromosome behavior in meiotic prophase I in the East-Asiatic mouse Apodemus peninsulae (Muridae, Rodentia). Cytogenet. Cell Genet. 48(3): 183-7. Available from http://www.ncbi.nlm.nih.gov/pubmed/3234042 [accessed 22 December 2016].

Lemke, J., Claussen, J., Michel, S., Chudoba, I., Mühlig, P., Westermann, M., Sperling, K., Rubtsov, N., Grummt, U., Ullmann, P., Kromeyer-Hauschild, K., Liehr, T., Claussen, U., and $\mathrm{Mu}, \mathrm{P} .2002$. The DNA-based structure of human chromosome 5 in interphase. Am. J. Hum. Genet. 71(5): 1051-9. doi:10.1086/344286.

Liehr, T. 2014. Benign \& Pathological Chromosomal Imbalances. In Microscopic and Submicroscopic Copy Number Variations (CNVs) in Genetics and Counseling. Academic Press, New York. pp. 121-126. doi:10.1016/B978-0-12-404631-3.00006-4.

Malygin, A.A., Graifer, D.M., Zenkova, M.A., Mamaev, S.V., and Karpova, G.G. 1992. Affinity modification of $80 \mathrm{~S}$ ribosomes from human placenta by derivatives of tri- and hexauridylates as mRNA analogs. Mol Biol. 26(2): 369-377.

Manterola, M., Page, J., Vasco, C., Berríos, S., Parra, M.T., Viera, A., Rufas, J.S., Zuccotti, M., Garagna, S., and Fernández-Donoso, R. 2009. A high incidence of meiotic silencing of unsynapsed chromatin is not associated with substantial pachytene loss in heterozygous male mice carrying multiple simple Robertsonian translocations. PLoS Genet. 5(8): e1000625. doi:10.1371/journal.pgen.1000625. 
Manvelyan, M., Hunstig, F., Bhatt, S., Mrasek, K., Pellestor, F., Weise, A., Simonyan, I., Aroutiounian, R., and Liehr, T. 2008. Chromosome distribution in human sperm - a 3D multicolor banding-study. Mol. Cytogenet. 1(1): 25. doi:10.1186/1755-8166-1-25.

Nystedt, B., Street, N.R., Wetterbom, A., Zuccolo, A., Lin, Y.-C., Scofield, D.G., Vezzi, F., Delhomme, N., Giacomello, S., Alexeyenko, A., Vicedomini, R., Sahlin, K., Sherwood, E., Elfstrand, M., Gramzow, L., Holmberg, K., Hällman, J., Keech, O., Klasson, L., Koriabine, M., Kucukoglu, M., Käller, M., Luthman, J., Lysholm, F., Niittylä, T., Olson, A., Rilakovic, N., Ritland, C., Rosselló, J. a, Sena, J., Svensson, T., Talavera-López, C., Theißen, G., Tuominen, H., Vanneste, K., Wu, Z.-Q., Zhang, B., Zerbe, P., Arvestad, L., Bhalerao, R., Bohlmann, J., Bousquet, J., Garcia Gil, R., Hvidsten, T.R., de Jong, P., MacKay, J., Morgante, M., Ritland, K., Sundberg, B., Thompson, S.L., Van de Peer, Y., Andersson, B., Nilsson, O., Ingvarsson, P.K., Lundeberg, J., and Jansson, S. 2013. The Norway spruce genome sequence and conifer genome evolution. Nature. 497(7451): 579-84. doi:10.1038/nature12211.

Rubtsov, N., Karamysheva, T., Andreenkova, O., Bochkaerev, M., Kartavtseva, I., Roslik, G., and Borissov, Y. 2004. Comparative analysis of micro and macro B chromosomes in the Korean field mouse Apodemus peninsulae (Rodentia, Murinae) performed by chromosome microdissection and FISH. Cytogenet. Genome Res. 106(2-4): 289-294. doi:10.1159/000079301.

Rubtsov, N., Karamysheva, T., Bogdanov, A., Likhoshvay, T., and Kartavtseva, I. 2011. Comparative FISH analysis of C-positive regions of chromosomes of wood mice (Rodentia, Muridae, Sylvaemus). Russ. J. Genet. 47(9): 1096-1110. doi:10.1134/S1022795411090158. Rubtsov, N., Kartavtseva, I., Roslik, G., Karamysheva, T., Pavlenko, M., Iwasa, M., and Koh, H. 2015. Features of the B chromosome in Korean field mouse Apodemus peninsulae (Thomas, 1906) from Transbaikalia and the Far East identified by the FISH method. Russ. 
J. Genet. 51(3): 278-288. doi:10.1134/S1022795415030114.

La Salle, S., Sun, F., and Handel, M.A. 2009. Isolation and Short-Term Culture of Mouse Spermatocytes for Analysis of Meiosis. In Meiosis: Volume 2, Cytological Methods. Edited by S. Keeney. Humana Press, New York. pp. 279-297. doi:10.1007/978-1-60761-103-5_17. Sambrook, J., and Pollack, R. 1974. Basic methodology for cell culture-cell transformation. Methods Enzym. 32: 583-592. Available from https://science.report/pub/31192762.

Scherthan, H., Jerratsch, M., Dhar, S., Wang, Y.A., Goff, S.P., and Pandita, T.K. 2000. Meiotic telomere distribution and Sertoli cell nuclear architecture are altered in Atm- and Atm-p53deficient mice. Mol. Cell. Biol. 20(20): 7773-83. doi:10.1128/MCB.20.20.7773-7783.2000.

Schneider, R., and Grosschedl, R. 2007. Dynamics and interplay of nuclear architecture, genome organization, and gene expression. Genes Dev. 21(23): 3027-43. doi:10.1101/gad.1604607.

Sciurano, R., Rahn, M., Rey-Valzacchi, G., and Solari, A.J. 2007. The asynaptic chromatin in spermatocytes of translocation carriers contains the histone variant $\gamma-\mathrm{H} 2 \mathrm{AX}$ and associates with the XY body. Hum. Reprod. 22(1): 142-150. doi:10.1093/humrep/del330.

Solovei, I., Cavallo, A., Schermelleh, L., Jaunin, F., Scasselati, C., Cmarko, D., Cremer, C., Fakan, S., and Cremer, T. 2002a. Spatial preservation of nuclear chromatin architecture during three-dimensional fluorescence in situ hybridization (3D-FISH). Exp. Cell Res. 276(1): 10-23. doi:10.1006/excr.2002.5513.

Solovei, I., Walter, J., Cremer, M., Habermann, H., Schermelleh, L., and Cremer, T. 2002 b. FISH on three-dimensionally preserved nuclei. In FISH: A practical approach. Edited by B. Beatty, S. Mai, J. Squire. Oxford University Press, Oxford. pp. 119-157.

Solovei, I., Schermelleh, L., Düring, K., Engelhardt, A., Stein, S., Cremer, C., and Cremer, T. 2004. Differences in centromere positioning of cycling and postmitotic human cell types. Chromosoma 112(8): 410-423. doi:10.1007/s00412-004-0287-3.

Torgasheva, A.A., Rubtsov, N.B., and Borodin, P.M. 2013. Recombination and synaptic 
adjustment in oocytes of mice heterozygous for a large paracentric inversion. Chromosom. Res. 21(1): 37-48.

Trifonov, V.A., Perelman, P.L., Kawada, S.I., Iwasa, M.A., Oda, S.I., and Graphodatsky, A.S. 2002. Complex structure of B-chromosomes in two mammalian species: Apodemus peninsulae (Rodentia) and Nyctereutes procyonoides (Carnivora). Chromosom. Res. 10(2): 109-116. doi:10.1023/A:1014940800901.

Turner, J.M., Mahadevaiah, S.K., Fernandez-Capetillo, O., Nussenzweig, A., Xu, X., Deng, C.X., and Burgoyne, P.S. 2005. Silencing of unsynapsed meiotic chromosomes in the mouse. Nat Genet. 37(1): 41-47. doi:ng1484 [pii]\r10.1038/ng1484.

Volobuev, V.T., and Timina, N.I. 1979. Unusually high number of B-chromosomes and mosaicism among them in the Asiatic forest mouse Apodemus peninsulae (Rodentia, Muridae). Tsitol. $\quad$ Genet. 14(3): 43-5. Available from http://www.ncbi.nlm.nih.gov/pubmed/7414685 [accessed 22 December 2016].

Weierich, C., Brero, A., Stein, S., Von Hase, J., Cremer, C., Cremer, T., and Solovei, I. 2003. Three-dimensional arrangements of centromeres and telomeres in nuclei of human and murine lymphocytes. Chromosom. Res. 11(5): 485-502. doi:10.1023/A:1025016828544.

Williams, R.R.E., Broad, S., Sheer, D., and Ragoussis, J. 2002. Subchromosomal positioning of the epidermal differentiation complex (EDC) in keratinocyte and lymphoblast interphase nuclei. Exp. Cell Res. 272(2): 163-75. doi:10.1006/excr.2001.5400.

Wójcik, J.M., Wójcik, A.M., Macholán, M., Piálek, J., and Zima, J. 2004. The mammalian model for population studies of B chromosomes: The wood mouse (Apodemus). Cytogenet. Genome Res. 106(2-4): 264-270. doi:10.1159/000079297.

Yaffe, E., and Tanay, A. 2011. Probabilistic modeling of Hi-C contact maps eliminates systematic biases to characterize global chromosomal architecture. Nat. Genet. 43(11): 1059-65. doi:10.1038/ng.947. 
Zima, J., and Macholan, M. 1995. B chromosomes in the wood mice (genus Apodemus). Acta Theriol. 40: 75-86. 


\section{FIGURE LEGENDS}

Fig 1.

FISH-results of PCP11-AC, PCP11-B2pq and WCP-9B8 on metaphase chromosomes of A. peninsulae prepared from bone marrow cells show different number, size and DNA content of Bs in the studied specimens:

(a-c) Metaphase spreads from the specimen \#1 (Ape 5) (a), \#6 (Ape 6), and \#1 (Ape 1) (c). Arrows point macro-Bs; arrowheads point micro-Bs; sex chromosomes are marked with X and Y; In (a) the thick arrow points the region on the B that was not painted by microdissected DNA probes. (d) Complete sets of Bs in all studied specimens (Ape 1 - Ape 10).

FISH signals are shown with pseudo colors as denoted on the plates. Chromosomes were counterstained with DAPI (blue).

\section{Fig 2.}

The Bs of specimens Ape3 (a-c) and Ape 8 (d-f).

a, d) Metaphase spreads prepared from bone marrow cells. FISH-results of PCP11-B2pq (red) and WCP-9B8 (green) on metaphase chromosomes. Arrows point macro-Bs; arrowheads point micro-Bs; sex chromosomes are marked with $\mathrm{X}$ and $\mathrm{Y}$;

b, e) Maximum intensity projection of laser scanning microscopy of two-color 3D-FISH with PCP11-B2pq (red) and WCP-9B8 (green) on spermatocyte interphase nucleus;

c, f) 3D-reconstruction of laser scanning microscopy of two-color 3D-FISH with PCP11B2pq (red) and WCP-9B8 (green) on spermatocyte interphase nucleus.

Chromosomes and nuclei were counterstained with DAPI (blue) 


\section{Fig 3.}

3D-reconstruction of laser scanning microscopy of three-color 3D-FISH with PCP11B2pq (red), WCP-9B8 (green), and PCP11-AC, (yellow) on spermatocyte nuclei of specimens characterized by different number and size of the Bs.

a) Nucleus of the specimen $\# 5$ containing 6 macro-Bs.

b) Nucleus of the specimen \#9 containing 2 macro-Bs and 3 micro-Bs.

3D-reconstruction of interphase nuclei shows the association of $\mathrm{Bs}$ of all types with Cpositive regions of A-chromosomes. Arrows marked as cen point $\mathrm{C}$ positive regions of $\mathrm{A}$ chromosomes.

Fig. 4.

3D-reconstruction of fibroblast interphase nuclei of specimens \#6 (a) and \#10 (b) characterized by Bs different in number, size, and DNA content which were obtained after laser scanning microscopy of 3D-FISH with PCP11-B2pq/WCP-9B8 (green), and PCP11-AC (yellow) and immunostaining of nucleoli with mouse-anti-B23 antibody (red). Nuclei were counterstained with DAPI (blue)

\section{Fig. 5}

Visualization of the central synaptonemal complex element (with SYCP1, red), lateral synaptonemal complex element (with SYCP3, blue) and phosphorylated histone H2A.X (with $\gamma \mathrm{H} 2 \mathrm{~A} . \mathrm{X}$, green) in a mid-pachytene spermatocyte. Univalents and bivalents formed by B chromosomes were revealed. The arrows point the Bs. Sex bivalent is marked with XY. A merged figure and three figures of single channels are shown. 
Table 1. Detailed information about karyotype features of studied individuals of $A$. peninsulae (Ape) including content variation and B-chromosome morphology, number of cells analyzed by FISH and specific signal counts for C-heterochromatic regions (cen), B-arm specific repeats type 1 (B1) and type 2 (B2).

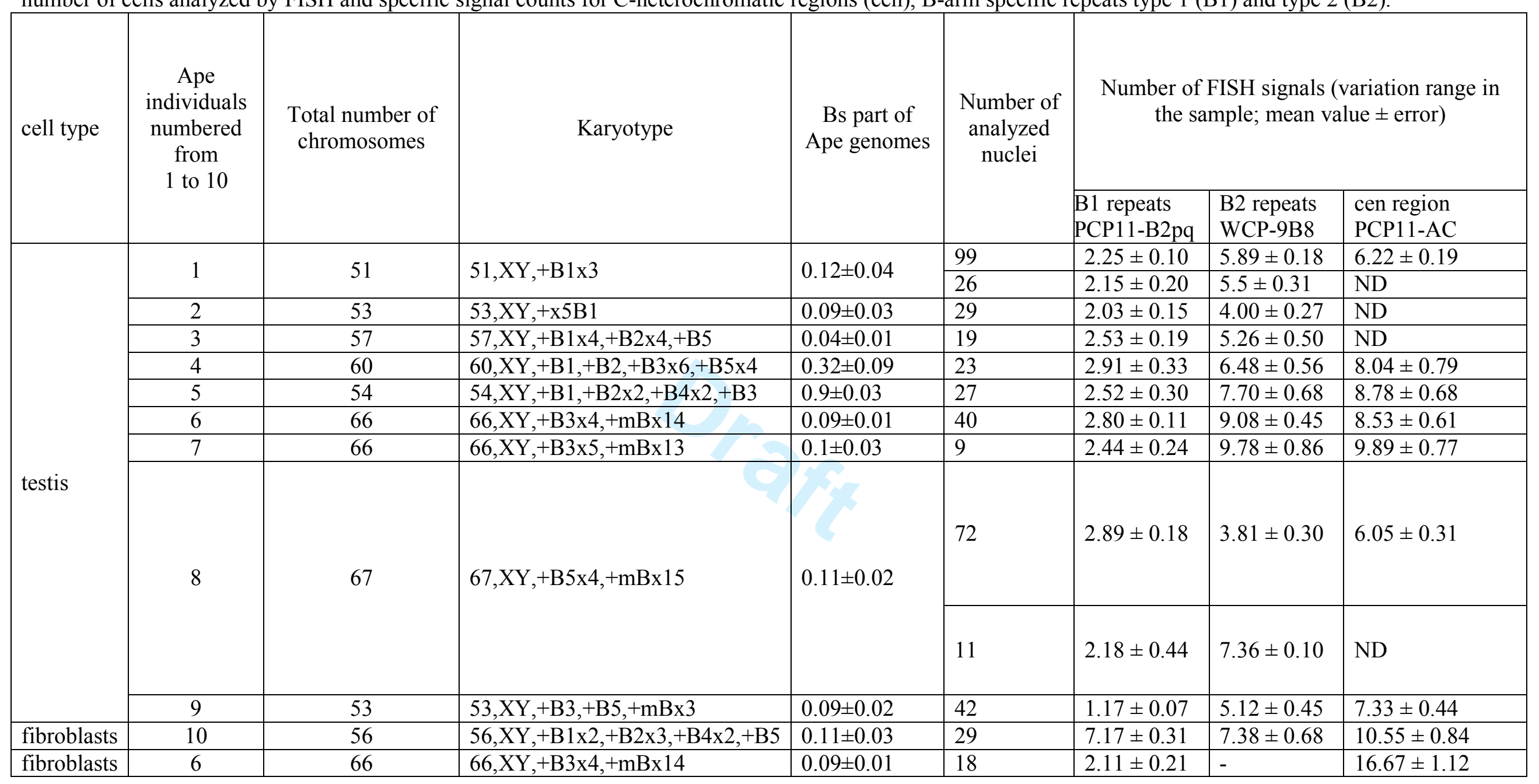

Abbreviations: B1 = large double-armed B; B2 = medium-size double-armed B; B3 = small double-armed B; B4 = medium-size acrocentric B; B5 = small acrocentric $\mathrm{B} ; \mathrm{mB}=$ micro $\mathrm{B} ; \mathrm{ND}=$ not done 

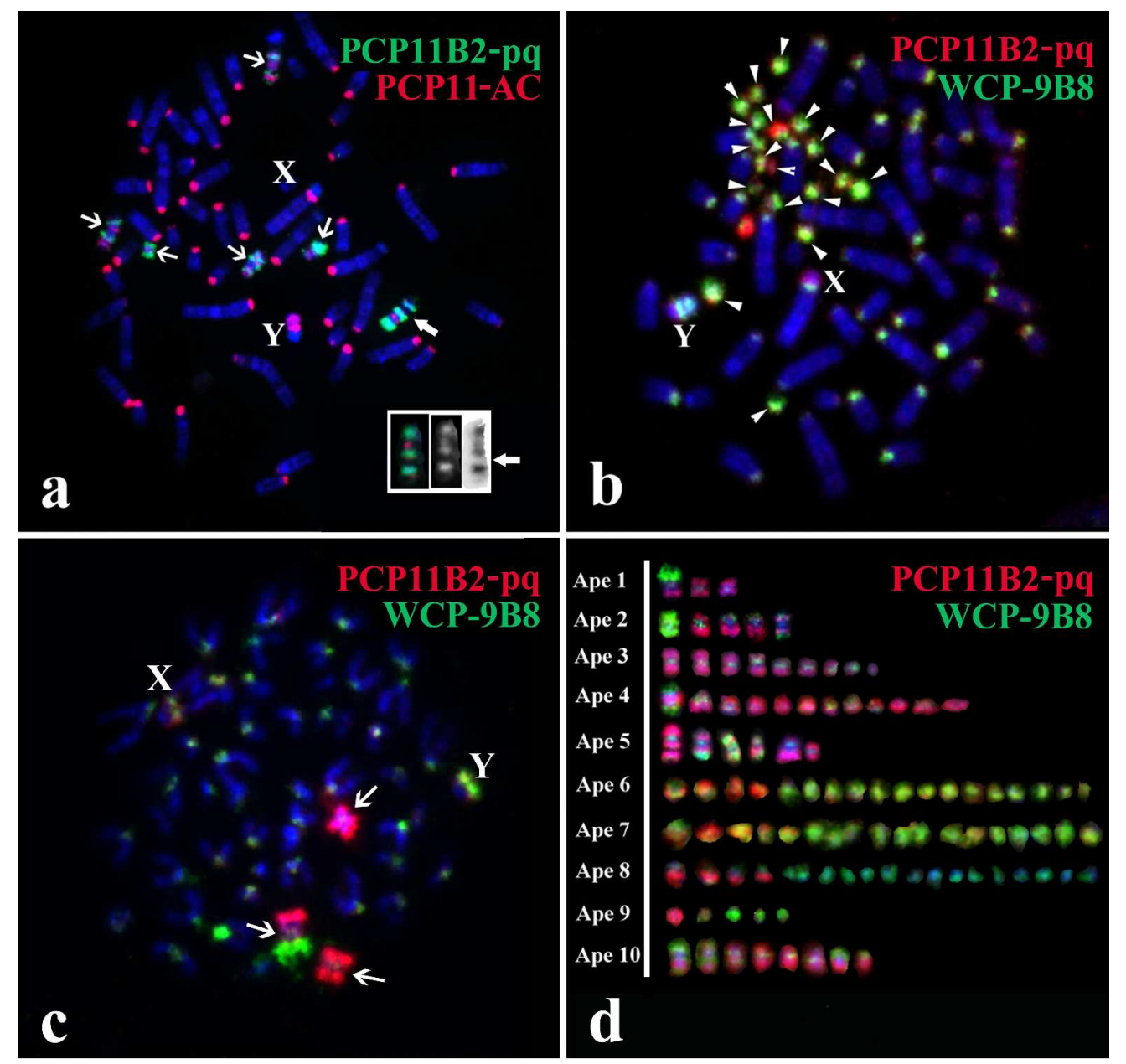

FISH-results of PCP11-AC, PCP11-B2pq and WCP-9B8 on metaphase chromosomes of A. peninsulae prepared from bone marrow cells show different number, size and DNA content of Bs in the studied specimens:

(a-c) Metaphase spreads from the specimen \#1 (Ape 5) (a), \#6 (Ape 6), and \#1 (Ape 1) (c). Arrows point macro-Bs; arrowheads point micro-Bs; sex chromosomes are marked with $X$ and $Y$; In (a) the thick arrow points the region on the $B$ that was not painted by microdissected DNA probes. (d) Complete sets of Bs in all studied specimens (Ape 1 - Ape 10).

FISH signals are shown with pseudo colors as denoted on the plates. Chromosomes were counterstained with DAPI (blue).

$423 \times 405 \mathrm{~mm}(300 \times 300 \mathrm{DPI})$ 

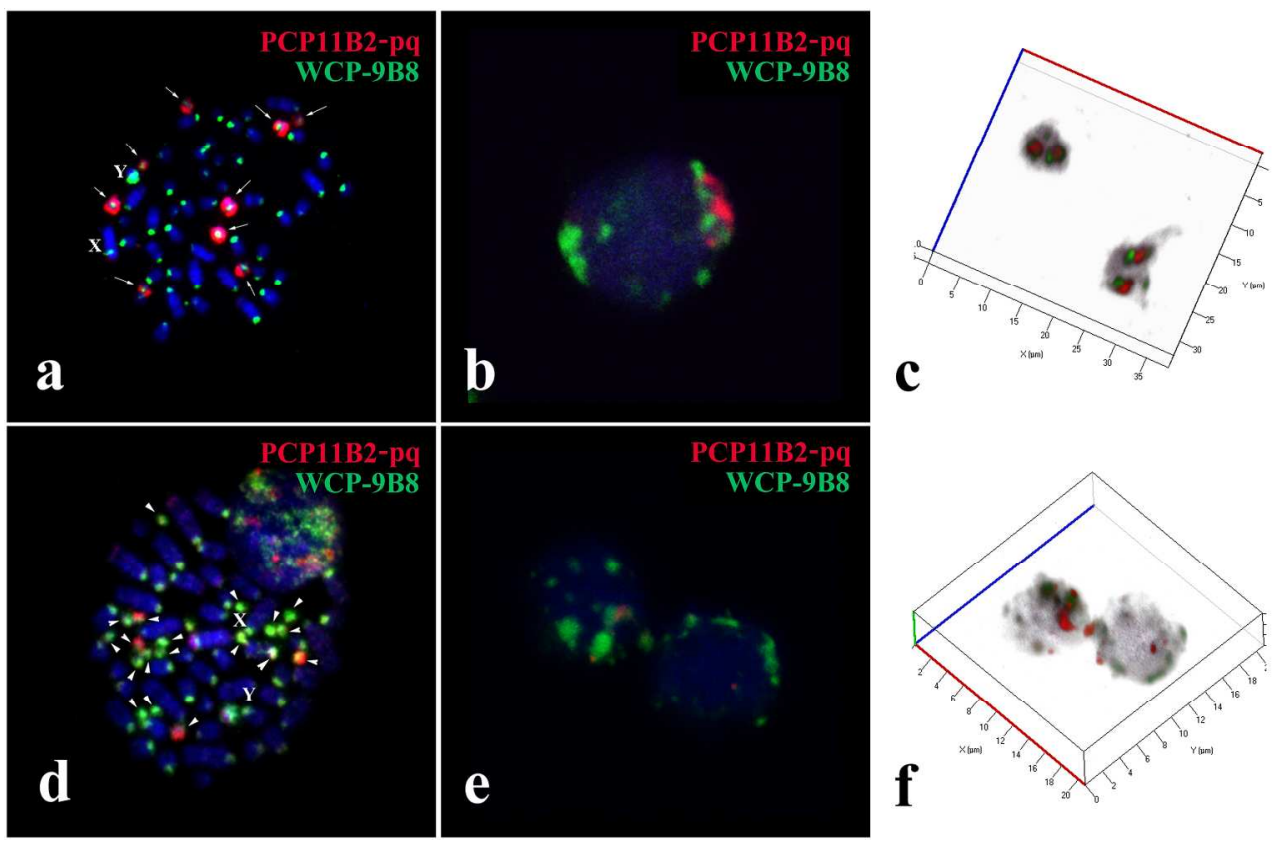

The Bs of specimens Ape3 (a-c) and Ape 8 (d-f).

a, d) Metaphase spreads prepared from bone marrow cells. FISH-results of PCP11-B2pq (red) and WCP-9B8 (green) on metaphase chromosomes. Arrows point macro-Bs; arrowheads point micro-Bs; sex chromosomes are marked with $\mathrm{X}$ and $\mathrm{Y}$;

b, e) Maximum intensity projection of laser scanning microscopy of two-color 3D-FISH with PCP11-B2pq (red) and WCP-9B8 (green) on spermatocyte interphase nucleus;

C, f) 3D-reconstruction of laser scanning microscopy of two-color 3D-FISH with PCP11-B2pq (red) and WCP9B8 (green) on spermatocyte interphase nucleus.

Chromosomes and nuclei were counterstained with DAPI (blue) 


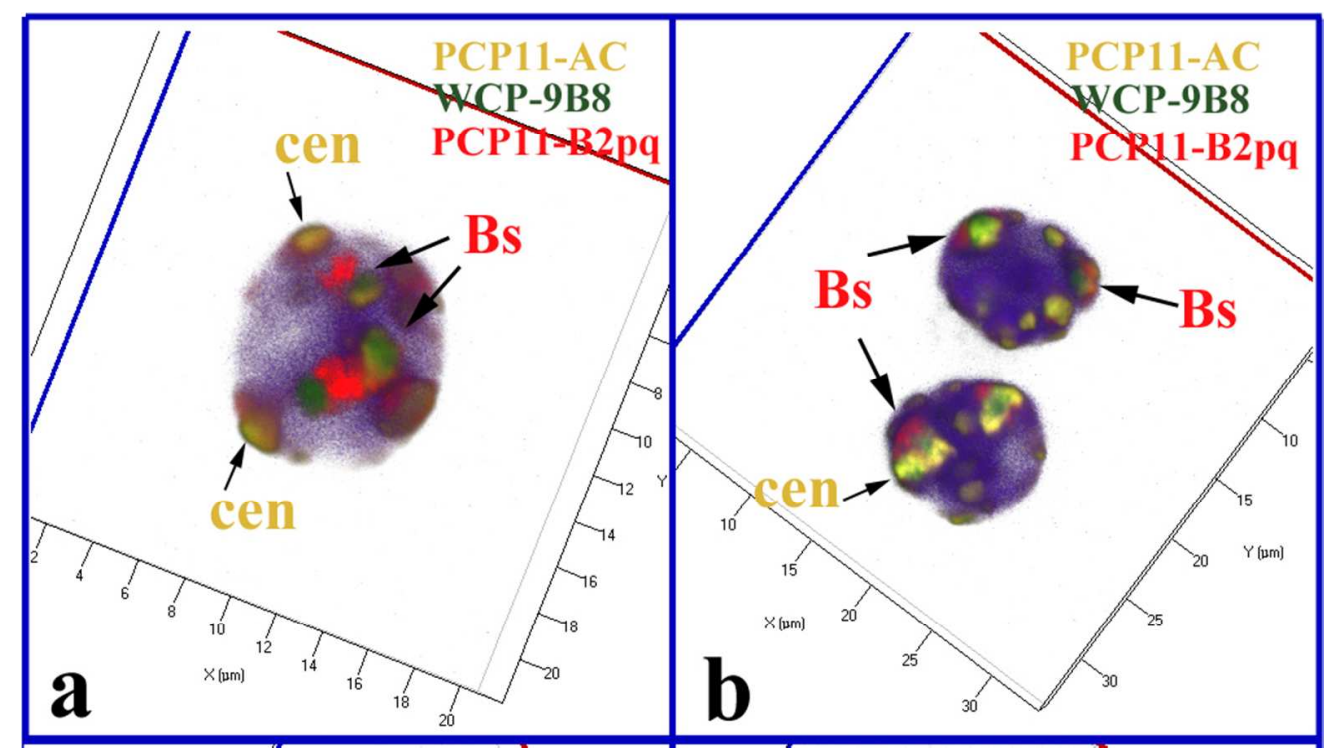

3D-reconstruction of laser scanning microscopy of three-color 3D-FISH with PCP11-B2pq (red), WCP-9B8 (green), and PCP11-AC, (yellow) on spermatocyte nuclei of specimens characterized with Bs different in number, size, and DNA content.

a) Nucleus of the specimen \# 5 containing 6 macro-Bs.

b) Nucleus of the specimen \#9 2 macro-Bs and 3 micro-Bs.

3D-reconstruction of interphase nuclei shows the association of Bs of all types with C-positive regions of Achromosomes. Arrows marked as cen point $\mathrm{C}$ positive regions of $\mathrm{A}$ chromosomes.

$354 \times 200 \mathrm{~mm}(72 \times 72$ DPI $)$ 


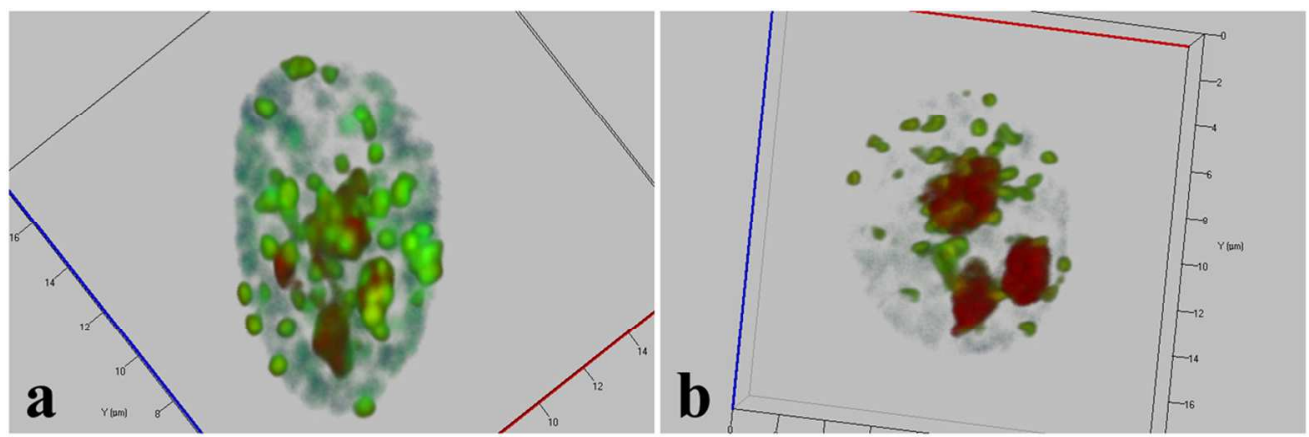

3D-reconstruction of fibroblast interphase nuclei of specimens \#6 (a) and \#10 (b) characterized by Bs different in number, size, and DNA content which were obtained after laser scanning microscopy of 3D-FISH with PCP11-B2pq/WCP-9B8 (green), and PCP11-AC (yellow) and immune staining of nucleoli with mouseanti-B23 antibody (red). Nuclei were stained with DAPI (blue)

$216 \times 71 \mathrm{~mm}(150 \times 150 \mathrm{DPI})$ 

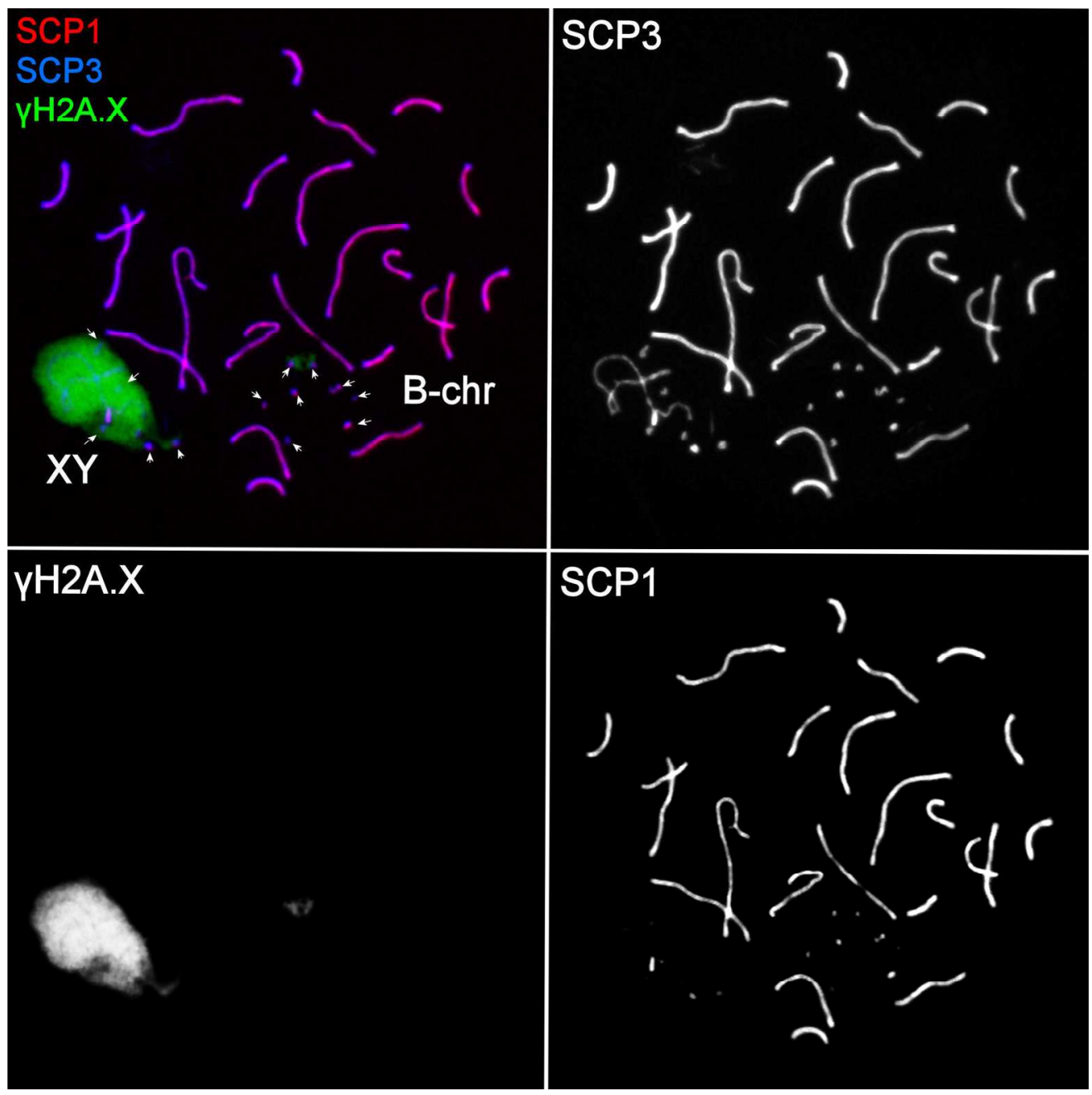

Visualization of the central synaptonemal complex element (with SYCP1, red), lateral synaptonemal complex element (with SYCP3, blue) and phosphorylated histone H2A.X (with YH2A.X, green) in a mid-pachytene spermatocyte. Univalents and bivalents formed by B chromosomes were revealed. The arrows indicate Bs. Sex bivalent is marked with XY. A merged figure and three figures of single channels are shown.

$$
158 \times 158 \mathrm{~mm}(300 \times 300 \mathrm{DPI})
$$

